\title{
Aerosolized perfluorocarbon improves gas exchange and pulmonary mechanics in preterm lambs with severe respiratory distress syndrome
}

\author{
Xabier Murgia' ', Victoria Mielgo' ${ }^{1}$, Adolf Valls-i-Soler ${ }^{2}$, Estibaliz Ruiz-del-Yerro' and Carmen Rey-Santano'
}

BACKGROUND: Aerosolized perfluorocarbon (PFC) has been proposed as an alternative method of PFC administration; however, the efficacy of aerosolized PFC in a preterm animal model has not yet been demonstrated.

METHODS: Twelve preterm lambs were randomized to two groups: a perfluorodecalin (PFD) aerosol group $(n=6)$ receiving $10 \mathrm{ml} / \mathrm{kg} / \mathrm{h}$ of PFD delivered by an intratracheal inhalation catheter followed by $4 \mathrm{~h}$ of mechanical ventilation (MV) or the control group, in which animals $(n=6)$ were managed for $6 \mathrm{~h}$ with MV. Gas exchange, pulmonary mechanics, cardiovascular parameters, and cerebral blood flow (CBF) were measured.

RESULTS: Both groups developed hypoxia, hypercarbia, and acidosis at baseline. Aerosolized PFD improved oxygenation $(P<0.0001)$ and pulmonary mechanics $(P<0.0001)$ and changed carbon dioxide values to normal physiological levels, unlike the treatment given to the controls $(P<0.0003)$. The time course of mean arterial blood pressure and CBF were significantly affected by PFD aerosolization, especially during the first hour of life. CBF gradually decreased during the first hour in the PFD aerosol group and remained stable until the end of the follow-up, whereas CBF remained higher in the control group $(P<0.0028)$.

CONCLUSION: Aerosolized PFD improves pulmonary function in preterm lambs and should be further investigated as an alternative mode of PFC administration.

$\mathbf{T}$ he biophysical properties of perfluorocarbons (PFCs) include low surface tension, a relatively high density (almost twice that of biological fluids), and high solubility for oxygen and carbon dioxide (1). Several researchers have explored how these properties might be exploited to assist with ventilation and have demonstrated that intrapulmonary delivery of PFC is beneficial for the treatment of various pulmonary diseases (2-4) including neonatal respiratory distress syndrome (RDS) $(5,6)$.

The most common mode of PFC administration is partial liquid ventilation (PLV) (7). In this technique, the lungs are filled with PFC to their functional residual capacity, and tidal volumes of gas are exchanged with a conventional mechanical ventilator. Although this technique has shown promising results in various animal models of lung injury (2-4,7-10), clinical trials have failed to demonstrate that PLV is better than standard care for the treatment of acute RDS (11).

Aerosol delivery has been proposed as a new experimental method for the administration of PFCs (1). To date, however, the experimental results on PFC aerosolization remain controversial, varying from no effect at all (12), to better pulmonary response to aerosolized PFC than to PLV (1). Such inconsistency might be partially explained by differences in aerosol devices (13), the biophysical properties of PFCs $(13,14)$, the time of aerosolization, and the degree of lung injury of the animal model used.

So far, therapeutic applications of aerosolized PFC have been described in relation to the treatment of acute lung injury in adult $(15,16)$ and pediatric models $(1)$. In the future, aerosolized PFC might be applicable for the treatment of preterm infants with surfactant deficiency. To the best of our knowledge, however, no efficacy studies have yet been conducted in preterm animal models of severe surfactant deficiency that would further support this hypothetical application. Because the pathophysiological mechanism and injury pattern of RDS differ from those observed in adult or pediatric acute RDS, the therapeutic response to aerosolized PFC might also be different. Therefore, this study was designed to investigate the efficacy of therapy with aerosolized PFC in preterm lambs with severe RDS.

\section{RESULTS}

No significant differences were found between groups in body weight, or in gas exchange or cardiovascular parameters in fetal life. All the animals survived the entire protocol in the perfluorodecalin (PFD) aerosol group. One animal in the control group died after $180 \mathrm{~min}$ of intermittent mechanical ventilation (IMV) after a period of extremely low systemic arterial blood pressure that was unresponsive to infusions of dopamine (up to $10 \mu \mathrm{g} / \mathrm{kg} / \mathrm{min}$ ).

\footnotetext{
${ }^{1}$ Research Unit for Experimental Neonatal Respiratory Physiology, Cruces University Hospital, Bizkaia, Spain; ${ }^{2}$ Neonatal Intensive Care Unit, Cruces University Hospital, Bizkaia, Spain. Correspondence: Xabier Murgia (xabier.murgiaesteve@osakidetza.net)
} 


\section{Gas Exchange}

Aerosolized PFD significantly improved oxygenation. At baseline, both groups showed low $\mathrm{PO}_{2}$ /fraction of inspired oxygen $\left(\mathrm{FiO}_{2}\right)$ ratios, and these significantly improved $60 \mathrm{~min}$ after the start of PFC aerosol therapy as compared with untreated control animals. Further, oxygenation was significantly better in the PFD aerosol group for the remainder of the observation period (Table 1).

Immediately after birth, all animals developed hypercarbia (Figure 1b) and severe acidosis (Table 1). PFD aerosolization improved both arterial $\mathrm{pH}$ and $\mathrm{PCO}_{2}$ levels. At the end of the PFD aerosol therapy, $\mathrm{pH}$ and $\mathrm{PCO}_{2}^{2}$ had returned to the normal physiological range $\left(\mathrm{PCO}_{2}, 41 \pm 11 \mathrm{~mm} \mathrm{Hg} ; \mathrm{pH}\right.$, $7.40 \pm 0.12$ ) and remained stable until the end of the observation period. On the contrary, severe hypercarbia and acidosis persisted in untreated animals for the remainder of the experiment.

\section{Oxygenation Index and Ventilatory Efficacy Index}

Oxygenation index (OI) was high in both groups at baseline. Subsequently, OI decreased significantly after aerosolized PFD (Figure 1a), but remained extraordinarily high in the untreated control group. After withdrawal of the PFD aerosol treatment, and for the rest of the observation period, OI was significantly lower in the PFD aerosol group than the control group.

The ventilatory efficiency index showed a similar trend (Table 1): $60 \mathrm{~min}$ after baseline, the increase in ventilatory efficiency index was already significant in the PFD aerosol group as compared with the untreated control group. The difference continued to be significant until the end of the follow-up.

\section{Pulmonary Mechanics}

Initial mean dynamic compliance $\left(\mathrm{C}_{\text {dyn }}\right)$ was found to be extremely low in both groups. By $30 \mathrm{~min}$ of life, $\mathrm{C}_{\mathrm{dyn}}$ was significantly higher in animals treated with aerosolized PFD than in the untreated control animals (Figure 2). This difference also remained significant until the end of the follow-up.

The tidal volume $\left(\mathrm{V}_{\mathrm{T}}\right)$ showed a time course similar to that of $\mathrm{C}_{\mathrm{dyn}}$ (Table 1): it was initially low in both groups and increased significantly in the PFD aerosol group as compared with the control group at $60 \mathrm{~min}$ of life $(P<0.05$, one-factor ANOVA). After withdrawal of the PFD aerosol treatment, a $V_{T}$ of between 9 and $12 \mathrm{ml} / \mathrm{kg}$ was reached and maintained in the animals in this group. In contrast, a maximum $\mathrm{V}_{\mathrm{T}}$ of $5-6 \mathrm{ml} / \mathrm{kg}$ was achieved in the control group at some point between 4 and $5 \mathrm{~h}$ after baseline was established.

\section{Cardiovascular Profile}

Mean arterial blood pressure (MABP) was significantly affected by PFD aerosolization (Figure 3a); blood pressure in the control group was found to be significantly higher at $15 \mathrm{~min}$ following the establishment of baseline and significantly lower at 150 min than in the PFD aerosol group. In addition, a significantly higher heart rate was found in the untreated control group at $60 \mathrm{~min}$ as compared with animals undergoing aerosol therapy (Table 1).

Table 1. Time course of physiological measurements

\begin{tabular}{|c|c|c|c|c|c|c|c|c|}
\hline & B & $60 \mathrm{~min}$ & $120 \mathrm{~min}$ & $180 \mathrm{~min}$ & $240 \mathrm{~min}$ & $300 \mathrm{~min}$ & $360 \mathrm{~min}$ & $P$ value \\
\hline $\mathrm{PO}_{2} / \mathrm{FiO}_{2}$ & & & & & & & & $<0.0001$ \\
\hline Control & $20(3)$ & $40(8)$ & $36(6)$ & $50(18)$ & $48(17)$ & $54(27)$ & $40(15)$ & \\
\hline VEI & & & & & & & & $<0.0001$ \\
\hline Control & $0.03(0)$ & $0.02(0)$ & $0.03(0)$ & $0.04(0.01)$ & $0.03(0.01)$ & $0.03(0.01)$ & $0.02(0)$ & \\
\hline $\mathrm{pH}$ & & & & & & & & $<0.0003$ \\
\hline Control & $7.00(0.02)$ & $7.00(0.05)$ & $7.11(0.07)$ & $7.10(0.08)$ & $7.15(0.06)$ & $7.08(0.08)$ & $7.05(0.07)$ & \\
\hline PFD aerosol & $7.02(0.04)$ & $7.25(0.07)^{*}$ & $7.40(0.04)^{*}$ & $7.46(0.01)^{*}$ & $7.41(0.02)^{*}$ & $7.36(0.04)^{*}$ & $7.30(0.05)^{*}$ & \\
\hline $\mathrm{V}_{\mathrm{T}}(\mathrm{ml} / \mathrm{kg})$ & & & & & & & & $<0.0001$ \\
\hline Control & $2(0.4)$ & $3.5(0.4)$ & $4(0.4)$ & $5(0.4)$ & $5(0.4)$ & $5(0.4)$ & $5(0.4)$ & \\
\hline PFD aerosol & $15(0)$ & $16(0)$ & $16(0)$ & $15(0)$ & $15(0)$ & $15(0)$ & $15(0.4)$ & \\
\hline HR (bpm) & & & & & & & & 0.77 \\
\hline Control & $168(17)$ & $180(5)$ & $173(16)$ & $195(12)$ & $208(10)$ & $202(16)$ & 191(14) & \\
\hline PFD aerosol & $174(13)$ & $150(8)^{*}$ & $175(15)$ & $202(20)$ & $201(20)$ & $216(17)$ & 218(15) & \\
\hline
\end{tabular}




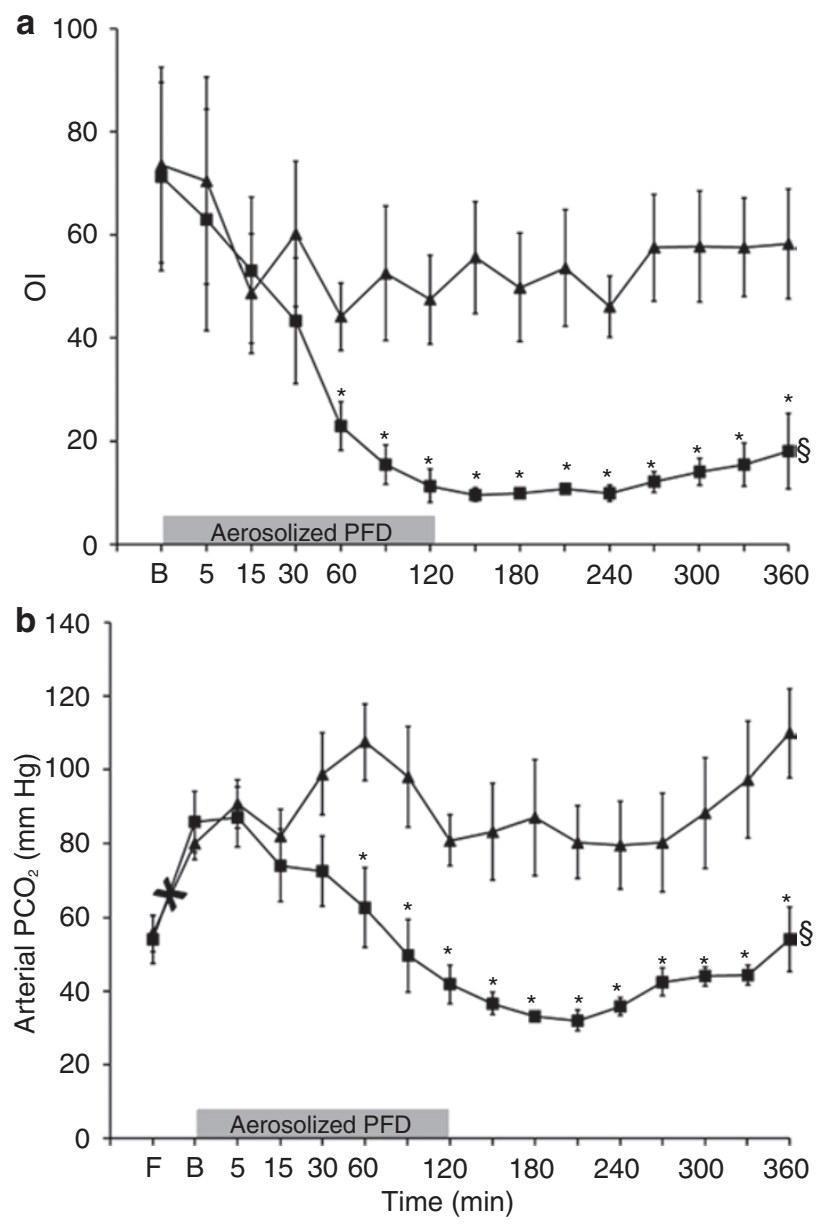

Figure 1. Oxygenation index and arterial $\mathrm{PCO}_{2}$. (a) Mean oxygenation index $(\mathrm{OI})$ and $(\mathbf{b})$ arterial $\mathrm{PCO}_{2}$ values in premature untreated lambs managed with mechanical ventilation (triangles, control) and in preterm lambs treated with aerosolized perfluorodecalin + mechanical ventilation (squares, perfluorodecalin (PFD) aerosol). On the $x$ axis in panels (a) and (b) , "B" represents baseline, after stabilization on mechanical ventilation and " $\mathrm{F}$ " indicates the arterial $\mathrm{PCO}_{2}$ values in fetal life. The gray horizontal bar represents the length of the aerosol treatment in the PFD aerosol group; lambs received $10 \mathrm{ml} / \mathrm{kg} / \mathrm{h}$ of aerosolized perfluorodecalin. The black " $X$ " represents the cut of the umbilical cord. Values are given as mean \pm SEM. $\S$ vs. control group, $P<0.001$ two-factor ANOVA for repeated measures as a function of time and group (baseline to $360 \mathrm{~min}$ ). ${ }^{*} \mathrm{vs}$. control group, $P<0.05$ single-factor ANOVA.

\section{Cerebral Blood Flow}

PFD aerosolization significantly affected the time course of cerebral blood flow (CBF) (Figure 3b). At baseline, both groups had similar CBF values; within the first hour, however, CBF gradually decreased in the PFD aerosol group, whereas it remained relatively high in the untreated control group. At 60 and 90 min significant differences were found between the groups, CBF being higher in control animals. Except at baseline, CBF values remained lower in animals treated with aerosolized PFD throughout the experiment.

\section{DISCUSSION}

This study shows for the first time that aerosolized PFC is effective in preterm lambs with severe RDS. Aerosolized

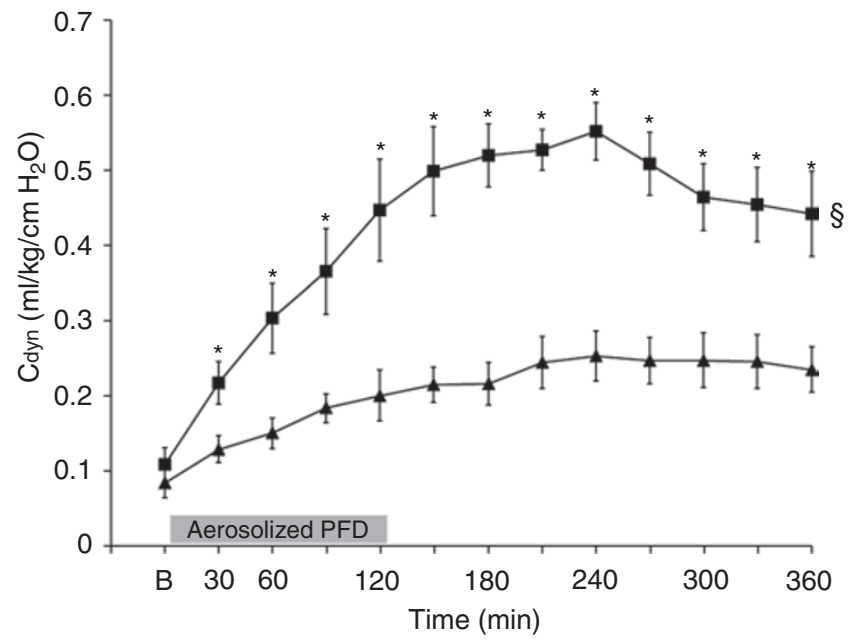

Figure 2. Mean dynamic compliance $\left(C_{d y n}\right)$ in premature untreated lambs managed with mechanical ventilation (triangles, control) and in preterm lambs treated with aerosolized perfluorodecalin + mechanical ventilation (squares, perfluorodecalin (PFD) aerosol). On the $x$ axis, "B" represents baseline, after stabilization on mechanical ventilation. The gray horizontal bar represents the length of the aerosol treatment in the PFD aerosol group; lambs received $10 \mathrm{ml} / \mathrm{kg} / \mathrm{h}$ of aerosolized perfluorodecalin. Values are given as mean \pm SEM. $\S$ vs. control group, $P<0.001$ two-factor ANOVA for repeated measures as a function of time and group (baseline to $360 \mathrm{~min}$ ). ${ }^{*}$ vs. control group, $P<0.05$ single-factor ANOVA.

PFD significantly improved gas exchange and pulmonary mechanics and resulted in a better outcome in terms of cardiovascular function as compared with untreated lambs, in which hypercarbia and hypoxia persisted during the entire observation period.

The benefits of intratracheally instilled PFC for respiratory support are well known (2-10). However, clinical trials have failed to demonstrate the superiority of PLV over standard care (11).

Currently, new methods of PFC administration are under investigation $(1,15,17)$. Aerosolized PFC is a promising new technique of PFC administration, but the available experimental data are not consistent. The lack of efficacy of aerosolized PFC shown by Kelly et al. (12) in surfactant-depleted rabbits contrasts with the overwhelmingly beneficial results reported by Kandler et al. (1) in surfactant-depleted piglets, with PFC delivered as an aerosol being better than PLV. The inconsistent results of these studies could be related to differences in the type of animal model and degree of injury, aerosol therapy devices (13), and the biophysical properties of the type of PFC used $(14,16)$.

For this study, an inhalation catheter $(1,14)$ placed into the endotracheal tube was used to produce PFD aerosols, with its aerosol generating tip placed above the carina. As compared with previous devices used to aerosolize PFC $(12,15)$, this system bypasses the oropharynx, avoiding the high deposition that tends to occur within the endotracheal tube (18). Therefore, particles $>5 \mu \mathrm{m}$ can reach the lungs and have a therapeutic effect (14). We hypothesize that the larger PFD particles (with an aerodynamic diameter $>5 \mu \mathrm{m}$ ) deposited 

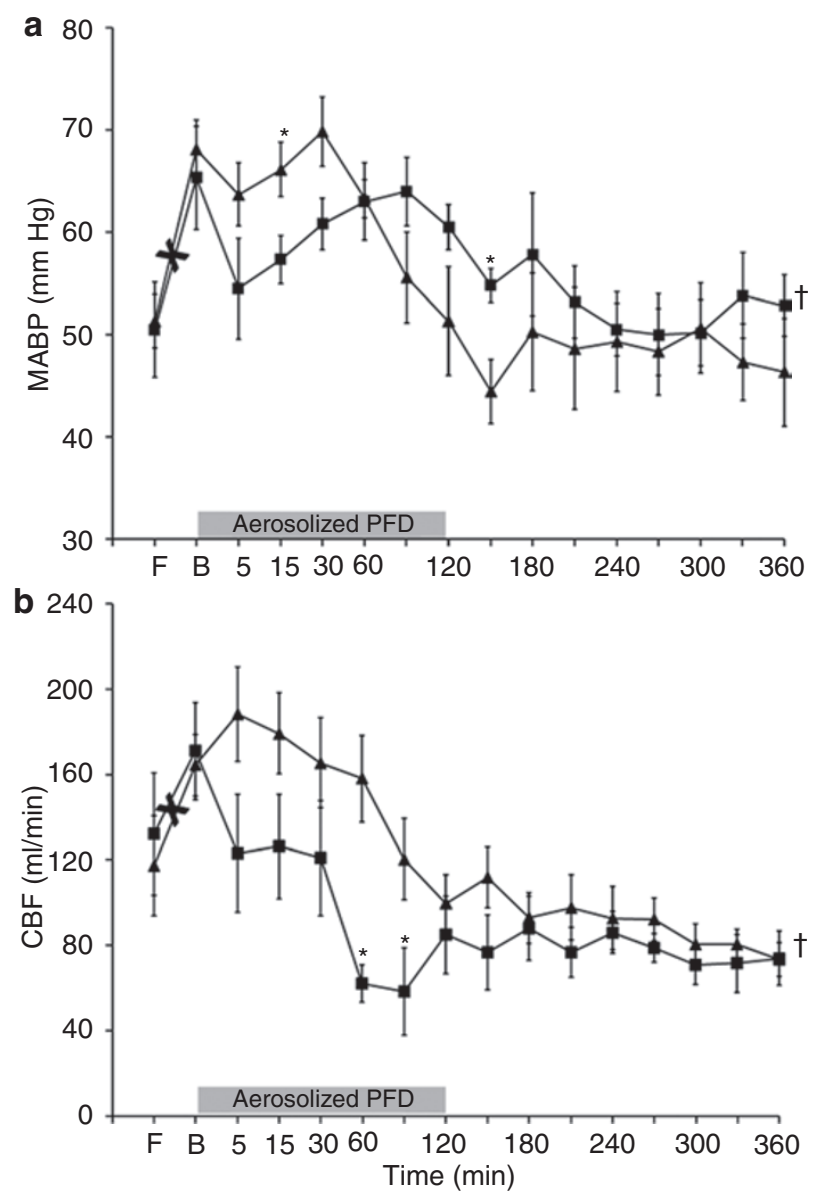

Figure 3. Mean arterial blood pressure (MABP) (a) and mean cerebral blood flow (CBF) (b) in premature untreated lambs managed with mechanical ventilation (triangles, control) and in preterm lambs treated with aerosolized perfluorodecalin + mechanichal ventilation (squares, perfluorodecalin (PFD) aerosol). On the $x$ axis in panels (a) and (b) , " $F$ " indicates the values in fetal life and " $B$ " represents baseline, after stabilization on mechanical ventilation. The gray horizontal bar represents the length of the aerosol treatment in the PFD aerosol group; lambs received $10 \mathrm{ml} / \mathrm{kg} / \mathrm{h}$ of aerosolized perfluorodecalin. The black " $X$ " represents the cut of the umbilical cord. Values are given as mean \pm SEM. $+v$ v. control group, $P<0.05$ two-factor ANOVA for repeated measures as a function of time and group (baseline to $360 \mathrm{~min}$ ). * vs. control group, $P<0.05$ single-factor ANOVA.

in the upper airways, whereas the finer particle fraction of PFD (with an aerodynamic diameter of $<5 \mu \mathrm{m}, 80 \%$ of particles) (14) penetrated further into the smaller airways, coating the alveolar surface with PFD droplets (1); this would allow the recruitment of more lung regions and an improvement in gas exchange and pulmonary mechanics by reducing surface tension.

The pulmonary improvement observed in the present study is in line with previous studies showing a gradual and sustained pulmonary improvement after PFC aerosolization $(1,15,19,20)$. This improvement is probably associated with a cumulative effect of PFC aerosol, which could have led to a gradual recruitment of collapsed lung regions. In fact, differences between groups in terms of OI and arterial $\mathrm{PCO}_{2}$ started to be significant $60 \mathrm{~min}$ after beginning the aerosol therapy. On the other hand, a shorter PFD aerosolization time was needed to improve lung mechanics; $\mathrm{C}_{\mathrm{dyn}}$ significantly had already improved in the PFC aerosol group by $30 \mathrm{~min}$ after the initiation of the therapy. On the basis of our bench studies $(14,21)$, at $30 \mathrm{~min}$ of therapy, a PFD dose of $\sim 3-3.5 \mathrm{ml} / \mathrm{kg}$ would have effectively reached the lung, which corresponds to the minimal dose of PFC to significantly improve $C_{d y n}$ according to Tütüncu et al. (9).

PFD was delivered at a rate of $10 \mathrm{ml} / \mathrm{kg} / \mathrm{h}$ for $2 \mathrm{~h}$, a dose that has been shown to improve oxygenation and lung function with various different PFCs $(1,19)$. Sharing the properties of low surface tension and a high oxygen and carbon dioxide solubility, different PFC compounds mainly differ in terms of molecular structure, vapor pressure, and kinematic viscosity (19). These parameters, in vivo, influence the initial pulmonary distribution of PFCs, redistribution over time within the lungs, intrapulmonary evaporative rate, and even the pulmonary gas exchange $(19,22)$. Therefore, different doses might be optimal for each PFC. For our study, a low-vapor-pressure and high-kinematic-viscosity PFC was chosen because it has been previously used for pulmonary support $(10,23)$ and because of its similarity to perfluorooctyl bromide (the only PFC purified to medical grade) in terms of surface tension, density, and vapor pressure (14). Because PFD shows a low vapor pressure and a relatively high kinematic viscosity, one could think that the beneficial effects of PFD aerosol might be related to a PLV-like effect derived from intrapulmonary accumulation of PFD over time. On the other hand, during the experiments no sign of intrapulmonary accumulation of PFD, such as a liquid meniscus at the end of expiration, were observed. Moreover, during PFC aerosolization there is unavoidable evaporative loss (14), and a great fraction of the PFC aerosol is expelled during the expiratory phase (24). Therefore, during PFC aerosolization the nominal dose $(10 \mathrm{ml} / \mathrm{kg} / \mathrm{h}$, in our study) is not equivalent to the PFC that actually reaches the lungs (21). On the basis of our bench studies $(14,21)$, we estimate that $\sim 65 \%$ of the nominal dose of PFD was effectively delivered to the lungs.

The aerosol therapy with PFD improved lung function and was well tolerated. In addition, aerosolized PFD altered the time course of MABP and CBF. At baseline, both groups showed a high CBF, derived from the acute hypoxia and hypercarbia inherent to severe lung immaturity. However, as hypoxia and hypercarbia resolved in animals treated with aerosolized PFD, CBF gradually decreased and remained stable for the rest of the observation period. In untreated lambs, however, the CBF remained relatively high (higher than in the treated group) for the entire observation period, especially during the first hour of life. This difference in CBF may be attributable to the high arterial $\mathrm{CO}_{2}$ levels observed in the untreated control group, which might further contribute to the development of brain injury (25). In addition, a higher CBF in the control group might also be explained by a physiological mechanism of blood redistribution toward the cerebral circulation to protect the brain from severe hypoxia $(26,27)$. In the animals in the untreated control group, MABP 
and heart rate might have increased in the first hour of life, as reflected in the significantly higher values observed in these animals at $15 \mathrm{~min}$ for MABP and at $60 \mathrm{~min}$ for heart rate, in an attempt to maintain cerebral blood supply that would guarantee sufficient oxygen supply during acute hypoxia. However, even though hypoxia, hypercarbia, and acidosis were persistent, animals in the control group appeared to be unable to sustain this mechanism over the time, with the MABP falling from $70 \pm 3$ at $30 \mathrm{~min}$, to $44 \pm 2 \mathrm{~mm} \mathrm{Hg}$ at $150 \mathrm{~min}$, and CBF decreasing from $165 \pm 21$ at $30 \mathrm{~min}$, to $112 \pm 14 \mathrm{ml} / \mathrm{min}$ at $60 \mathrm{~min}$. Despite a high level of ventilatory support, arterial $\mathrm{CO}_{2}, \mathrm{pH}$, and oxygen levels remained far from normal biological levels in the control group throughout the whole observation period, which further reveals the severe pulmonary immaturity found in the Basque Latxa breed of sheep at $133 \mathrm{~d}$ of gestational age.

In summary, our study has demonstrated that aerosolized PFC improves gas exchange and pulmonary mechanics in preterm lambs with severe RDS. These data suggest that PFC delivered as an aerosol might represent a new therapeutic approach for the treatment of RDS. Nevertheless, the limitations of our work have to be recognized. On the one hand, the pulmonary distribution of aerosolized PFD within the lungs was not assessed in the present work. Specifically, PFCs are immiscible in water and, to our knowledge, no substances can be dissolved in them; therefore, the methods previously used by our group to study pulmonary distribution were not useful in these experiments $(28,29)$. On the other hand, because the study was focused on the efficacy of aerosolized PFC, the control group was composed of untreated animals, which significantly differs from a clinical setting, where the subjects would almost certainly be spontaneously breathing. Future studies should elucidate whether aerosolized PFC is superior to PLV in preterm lambs, as previously found in a pediatric porcine model with surfactant depletion (1), and whether this therapeutic approach can avoid the "peridosing" adverse effects associated with PLV $(11,30)$. The potential additive effect of aerosolized PFC to surfactant therapy should be explored as well, as it has been demonstrated for PLV (31).

\section{METHODS}

\section{Experimental Subjects}

This study was conducted with 12 premature lambs $(3.6 \mathrm{~kg} \pm 0.1)$ of the Basque Latxa breed that were delivered at $133 \mathrm{~d}$ of gestation (term: $145 \mathrm{~d}$ ), a gestational age shown to produce severe pulmonary surfactant deficiency (28) and, therefore, to yield an adequate model to test the efficacy of aerosolized PFC as a rescue therapy. The experimental protocol was approved by the Animal Care Committee of Cruces University Hospital and met all the Spanish and European regulations for animal research (RD 1201/2005).

\section{Animal Preparation}

Ewes were sedated with xylazine (6-8 mg, i.m.) and ketamine $(5 \mathrm{mg} / \mathrm{kg}$, i.v.). Anesthesia was then maintained with propofol $(10 \mathrm{mg} / \mathrm{kg} / \mathrm{h}$, i.v.); Ringer's lactate solution was infused as needed. A tracheal tube (internal diameter: $8 \mathrm{~mm}$ ) was inserted into the trachea and connected to a volume-controlled ventilator (Julian, Draeger, Luebeck, Germany), to maintain adequate gas exchange (initial settings were as follows: rate of 30 breaths/min; peak inspiratory pressure/positive end expiratory pressure ratio of 14-16:2 $\mathrm{cm} \mathrm{H}_{2} \mathrm{O}$; inspiratory/expiratory ratio of $1: 2$; and $\mathrm{FiO}_{2}$ of 0.4-0.6. A peripheral arterial cannula (Insyte; BD, Madrid, Spain) was inserted to monitor MABP and heart rate as well as to obtain arterial blood samples.

With the ewe lying on its right side, the uterus was exposed with a lateral subcostal incision, and the head and neck of the fetal lambs were exteriorized. A tracheal tube (Hi-Lo Jet tracheal tube; internal diameter: $4.0 \mathrm{~mm}$; Mallinckrodt Medical, St Louis, MO) was inserted by tracheostomy, with its tip at the carina, and was tied around the trachea to prevent leaks. Lungs were allowed to drain slowly under gravity. End-hole catheters (8-French XRO umbilical catheters; Vygon, Ecouen, France) were inserted into the jugular vein and subclavian artery. An ultrasonic flow probe (MA 3 PS, Transonics, Ithaca, FL) was placed around the left carotid artery to continuously monitor the carotid blood flow $\left(\mathrm{Q}_{\mathrm{car}}\right)$. Lambs were given ketamine $(3 \mathrm{mg} / \mathrm{kg})$ and atracurium besylate $(4 \mathrm{mg} / \mathrm{kg})$ intravenously, and the umbilical cord was cut. They were weighed, dried, and placed in right lateral decubitus in a servo-controlled radiant warmer to maintain the rectal temperature at $38-39^{\circ} \mathrm{C}$. Then the tracheal tube was connected to a time-cycled, pressure-limited ventilator (Bourns BP-200; Beard Medical Systems, Riverside, CA), with the following initial settings: rate of 60 breaths/min; peak inspiratory pressure/positive end expiratory pressure of $35 / 5 \mathrm{~cm} \mathrm{H} O$; inspiratory/ expiratory ratio of $1: 2 ; \mathrm{FiO}_{2}$ of 1.0 ; and flow rate of $10 \mathrm{1} / \mathrm{min}$. After 10 min of stabilization on IMV, the baseline was established. Ventilator settings, including $\mathrm{FiO}_{2}$, were varied to try to maintain an arterial $\mathrm{PO}_{2}$ between 85 and $115 \mathrm{~mm} \mathrm{Hg}$ and $\mathrm{PCO}_{2}$ between 35 and $50 \mathrm{~mm} \mathrm{Hg}$. Ketamine was infused in $5 \%$ glucose $(4 \mathrm{mg} / \mathrm{kg} / \mathrm{h}$, i.v. $)$ and atracurium besylate as needed. If the MABP fell below $40 \mathrm{~mm}$ $\mathrm{Hg}$, dopamine was then infused at $5-10 \mu \mathrm{g} / \mathrm{kg} / \mathrm{min}$. Peak inspiratory pressure values higher than $40 \mathrm{~cm} \mathrm{H}_{2} \mathrm{O}$ were avoided in order to prevent pneumothorax.

\section{Study Design}

After baseline measurements, lambs were randomized to receive aerosolized PFC (PFD aerosol group) or not (control group). Lambs in the PFD aerosol group received $10 \mathrm{ml} / \mathrm{kg} / \mathrm{h}$ of perfluorodecalin (PFD; $\mathrm{C}_{10} \mathrm{~F}_{18}$ F2 Chemicals, Lancashire, UK; density at $25^{\circ} \mathrm{C}=$ $1.95 \mathrm{~g} / \mathrm{ml}$; kinematic viscosity $=2.7$ stokes; vapor pressure at $37{ }^{\circ} \mathrm{C}$ $=14 \mathrm{~mm} \mathrm{Hg}$; surface tension $=15$ dynes $/ \mathrm{cm}$; and oxygen solubility $=49 \mathrm{ml} / 100 \mathrm{ml}$ ) for $2 \mathrm{~h}$, via an intratracheal inhalation catheter (AeroProbe, Trudell Medical International, London, Ontario, Canada) with its aerosol generating tip placed $1 \mathrm{~mm}$ beyond the end of the endotracheal tube, followed by $4 \mathrm{~h}$ IMV. The control group was maintained on IMV for $6 \mathrm{~h}$.

Briefly, these inhalation catheters consist of several outer lumens, through which a driving gas passes at a high velocity, and a central lumen for the fluid that is to be aerosolized. Due to the large decrease in pressure (Bernoulli effect) created by the gas in the outer lumens, the liquid is drawn up and reduced to droplets of a respirable size range with associated gas flow as low as $1.23 \mathrm{l} / \mathrm{min}$ (14). This aerosol delivery system can deliver up to $2 \mathrm{ml}$ of PFD per minute during continuous aerosolization, with $80 \%$ of the particles having an aerodynamic diameter of $<5 \mu \mathrm{m}$ (14). In this study, aerosols were delivered only during inspiration.

\section{Physiological Measurements}

Arterial $\mathrm{pH}, \mathrm{PO}_{2}$, and $\mathrm{PCO}_{2}$ (GEM Premier 4000, Premier, San Diego, CA) and cardiovascular parameters (Intellivue MP70, Philips Healthcare, Eindhoven, The Netherlands) were measured 5, 15, and $30 \mathrm{~min}$ following the establishment of the baseline level, and then every 30 min until the end of the observation period of $6 \mathrm{~h}$.

The OI was calculated as: (mean airway pressure $\left(\mathrm{cm} \mathrm{H}_{2} \mathrm{O}\right) \times$ $\left.\mathrm{FiO}_{2}\right) /\left(\right.$ arterial $\left.\mathrm{PO}_{2}(\mathrm{~mm} \mathrm{Hg}) \times 100\right)$. To assess pulmonary ventilation independent of ventilator settings, the ventilatory efficiency index was calculated as $3,800 /$ (peak inspiratory pressure - positive end expiratory pressure) $\left(\mathrm{cm} \mathrm{H}_{2} \mathrm{O}\right) \times$ breath rate (breaths/min $) \times$ arterial $\mathrm{PCO}_{2}(\mathrm{~mm} \mathrm{Hg})$. 
$\mathrm{V}_{\mathrm{T}}, \mathrm{C}_{\mathrm{dyn}}$, and mean airway pressure were determined at baseline and then every $30 \mathrm{~min}$. A differential pressure transducer (range $0-71 \mathrm{~cm} \mathrm{H} \mathrm{H}_{2} \mathrm{O}$, Honeywell, Morristown, NJ) fitted to a pneumotachograph (Fleisch 000, Lausanne, Switzerland) was used to assess pulmonary mechanics. The data recorded were then processed following the method described by Álvarez et al. (32) for realtime monitoring of lung mechanics during both gas and liquid ventilation.

The carotid blood flow $\left(\mathrm{Q}_{\mathrm{car}}\right)$ of the left carotid artery was continuously measured. Because the blood flow of the left and right carotid arteries is equivalent in preterm lambs (33), total $Q_{\text {car }}$ was determined by multiplying by two the values registered in the left carotid artery. $\mathrm{CBF}$ was then calculated following the equation described by van Bel et al. (33): $\mathrm{CBF}=\left(\mathrm{Q}_{\text {car }}(\mathrm{ml} / \mathrm{min})-8.07\right) / 1.43$.

\section{Data Analysis and Statistics}

All values are given as mean \pm SEM. Intergroup comparisons at different time intervals were assessed by both one-factor and two-factor ANOVA to determine statistical differences between groups as a function of both time and group (repeated measures, baseline to $360 \mathrm{~min}$ ). These analyses were performed with Bonferroni-Dunn correction. A $P<0.05$ was considered to be significant (JMP8, Statistical Discovery, SAS, Cary, NC). The sample size was calculated on the basis of the means and $\mathrm{SD}$ of the $\mathrm{PO}_{2}, \mathrm{PCO}_{2}$, and $\mathrm{C}_{\mathrm{dyn}}$ values of preterm lambs with severe RDS after $3 \mathrm{~h}$ on mechanical ventilation (34). A sample size of 6 in each group is sufficient to detect a $50 \%$ difference with an a-error of 0.05 and power of $80 \%$.

\section{ACKNOWLEDGMENTS}

The excellent technical assistance of Francisco José Álvarez Díaz and Hector Lafuente is gratefully acknowledged.

\section{STATEMENT OF FINANCIAL SUPPORT}

This study was partially funded by the Carlos III Health Institute (grants FIS PI10/00943 and RD08/072 (SAMID Network: Maternal, Child Health and Development Network within the framework of the VI Spanish National R+D+i Plan 2008-2011)) and by the government of the Basque Country (grant 2007111046). The authors declared no conflict of interest.

\section{REFERENCES}

1. Kandler MA, von der Hardt K, Schoof E, Dötsch J, Rascher W. Persistent improvement of gas exchange and lung mechanics by aerosolized perfluorocarbon. Am J Respir Crit Care Med 2001;164:31-5.

2. Gastiasoro-Cuesta E, Alvarez-Díaz FJ, Arnaiz-Renedo A, et al. The cardiovascular effects of partial liquid ventilation in newborn lambs after experimental meconium aspiration. Pediatr Crit Care Med 2001; 2:334-9.

3. Hirschl RB, Parent A, Tooley R, et al. Liquid ventilation improves pulmonary function, gas exchange, and lung injury in a model of respiratory failure. Ann Surg 1995;221:79-88.

4. Guo ZL, Lu GP, Ren T, et al. Partial liquid ventilation confers protection against acute lung injury induced by endotoxin in juvenile piglets. Respir Physiol Neurobiol 2009;167:221-6.

5. Leach CL, Greenspan JS, Rubenstein SD, et al. Partial liquid ventilation with perflubron in premature infants with severe respiratory distress syndrome. The LiquiVent Study Group. N Engl J Med 1996;335:761-7.

6. Greenspan JS, Wolfson MR, Rubenstein SD, Shaffer TH. Liquid ventilation of human preterm neonates. J Pediatr 1990;117(1 Pt 1):106-11.

7. Fuhrman BP, Paczan PR, DeFrancisis M. Perfluorocarbon-associated gas exchange. Crit Care Med 1991;19:712-22.

8. Fujino Y, Goddon S, Chiche JD, Hromi J, Kacmarek RM. Partial liquid ventilation ventilates better than gas ventilation. Am J Respir Crit Care Med 2000;162(2 Pt 1):650-7.

9. Tütüncü AS, Faithfull NS, Lachmann B. Intratracheal perfluorocarbon administration combined with mechanical ventilation in experimental respiratory distress syndrome: dose-dependent improvement of gas exchange. Crit Care Med 1993;21:962-9.
10. Al-Rahmani A, Awad K, Miller TF, Wolfson MR, Shaffer TH. Effects of partial liquid ventilation with perfluorodecalin in the juvenile rabbit lung after saline injury. Crit Care Med 2000;28:1459-64.

11. Kacmarek RM, Wiedemann HP, Lavin PT, Wedel MK, Tütüncü AS, Slutsky AS. Partial liquid ventilation in adult patients with acute respiratory distress syndrome. Am J Respir Crit Care Med 2006;173:882-9.

12. Kelly KP, Stenson BJ, Drummond GB. Randomised comparison of partial liquid ventilation, nebulised perfluorocarbon, porcine surfactant, artificial surfactant, and combined treatments on oxygenation, lung mechanics, and survival in rabbits after saline lung lavage. Intensive Care Med 2000;26:1523-30.

13. Rüdiger M, Gregor T, Burkhardt W, Proquitté H, Wauer RR, Schmalisch G. Perfluorocarbon species and nebulizer type influence aerosolization rate and particle size of perfluorocarbon aerosol. J Crit Care 2004;19: $42-7$.

14. Murgia X, Gastiasoro E, Mielgo V, et al. Surfactant and perfluorocarbon aerosolization by means of inhalation catheters for the treatment of respiratory distress syndrome: an in vitro study. J Aerosol Med Pulm Drug Deliv 2011;24:81-7.

15. Ragaller M, Bleyl J, Tschö U, et al. Effects of inhalation of perfluorocarbon aerosol on oxygenation and pulmonary function compared to PGI2 inhalation in a sheep model of oleic acid-induced lung injury. Intensive Care Med 2001;27:889-97.

16. Meinhardt JP, Schmittner M, Herrmann P, Mailer M, Quintel M. Comparison of different inhalational perfluorocarbons in a rabbit model of acute lung injury. ASAIO J 2005;51:85-91.

17. Bleyl JU, Ragaller M, Tschö U, et al. Vaporized perfluorocarbon improves oxygenation and pulmonary function in an ovine model of acute respiratory distress syndrome. Anesthesiology 1999;91:461-9.

18. Miller DD, Amin MM, Palmer LB, Shah AR, Smaldone GC. Aerosol delivery and modern mechanical ventilation: in vitro/in vivo evaluation. Am J Respir Crit Care Med 2003;168:1205-9.

19. von der Hardt K, Kandler MA, Brenn G, et al. Comparison of aerosol therapy with different perfluorocarbons in surfactant-depleted animals. Crit Care Med 2004;32:1200-6.

20. Kandler MA, von der Hardt K, Gericke N, Chada M, Dötsch J, Rascher W. Dose response to aerosolized perflubron in a neonatal swine model of lung injury. Pediatr Res 2004;56:191-7.

21. Murgia X, Gastiasoro E, Mielgo V, et al. Surfactant and perfluorocarbon aerosolization during different mechanical ventilation strategies by means of inhalation catheters: an in vitro study. J Aerosol Med Pulm Drug Deliv 2012;25:23-31.

22. Miller TF, Milestone B, Stern R, Shaffer TH, Wolfson MR. Effects of perfluorochemical distribution and elimination dynamics on cardiopulmonary function. J Appl Physiol 2001;90:839-49.

23. Suh GY, Chung MP, Park SJ, et al. Partial liquid ventilation shows dosedependent increase in oxygenation with PEEP and decreases lung injury associated with mechanical ventilation. J Crit Care 2000;15:103-12.

24. Gregor T, Schmalisch G, Burkhardt W, Proquitté H, Wauer RR, Rüdiger M. Aerosolization of perfluorocarbons during mechanical ventilation: an in vitro study. Intensive Care Med 2003;29:1354-60.

25. Skov L, Hellström-Westas L, Jacobsen T, Greisen G, Svenningsen NW. Acute changes in cerebral oxygenation and cerebral blood volume in preterm infants during surfactant treatment. Neuropediatrics 1992; 23:126-30.

26. Ashwal S, Majcher JS, Longo LD. Patterns of fetal lamb regional cerebral blood flow during and after prolonged hypoxia: studies during the posthypoxic recovery period. Am J Obstet Gynecol 1981;139:365-72.

27. Cohn HE, Sacks EJ, Heymann MA, Rudolph AM. Cardiovascular responses to hypoxemia and acidemia in fetal lambs. Am J Obstet Gynecol 1974;120:817-24.

28. Gastiasoro-Cuesta E, Alvarez-Diaz FJ, Rey-Santano C, Arnaiz-Renedo A, Loureiro-Gonzalez B, Valls-i-Soler A. Acute and sustained effects of lucinactant versus poractant-alpha on pulmonary gas exchange and mechanics in premature lambs with respiratory distress syndrome. Pediatrics 2006;117:295-303.

29. Rey-Santano C, Alvarez-Diaz FJ, Mielgo V, et al. Bronchoalveolar lavage versus bolus administration of lucinactant, a synthetic surfactant 
in meconium aspiration in newborn lambs. Pediatr Pulmonol 2011; 46:991-9.

30. Kaisers U, Kelly KP, Busch T. Liquid ventilation. Br J Anaesth 2003;91:143-51.

31. Mrozek JD, Smith KM, Bing DR, et al. Exogenous surfactant and partial liquid ventilation: physiologic and pathologic effects. Am J Respir Crit Care Med 1997;156(4 Pt 1):1058-65.

32. Alvarez FJ, Gastiasoro E, Rey-Santano MC, Gomez-Solaetxe MA, Publicover NG, Larrabe JL. Dynamic and quasi-static lung mechan- ics system for gas-assisted and liquid-assisted ventilation. IEEE Trans Biomed Eng 2009;56:1938-48.

33. van Bel F, Roman C, Klautz RJ, Teitel DF, Rudolph AM. Relationship between brain blood flow and carotid arterial flow in the sheep fetus. Pediatr Res 1994;35:329-33.

34. Leach CL, Holm B, Morin FC $3^{\text {rd }}$, et al. Partial liquid ventilation in premature lambs with respiratory distress syndrome: efficacy and compatibility with exogenous surfactant. J Pediatr 1995;126: $412-20$. 